\title{
Estudios
}

\section{Fracaso institucional de un modelo teológico-cultural de Iglesia Factores sistémicos en la crisis de los abusos}

\author{
Carlos Schickendantr. \\ CENTRO TEOLÓGICO MANUEL LARRAÍN \\ UNIVERSIDAD ALBERTO HURTADO \\ cschickend@uahurtado.cl
}

Resumen: La cuestión del abuso sexual de menores constituye una de las crisis más significativas de la Iglesia Católica en la era moderna. En primer lugar, este artículo ofrece múltiples argumentos para la comprensión del asunto a partir de unos textos norteamericanos especializados. El segundo momento representa el núcleo de la contribución: con el análisis de varios informes de diferentes nacionalidades, particularmente australiano y alemán, se pone de relieve el aspecto institucional de lo sucedido en la Iglesia Católica, en especial sus disfunciones sistémicas que, como se muestra con diversos argumentos, converge con reflexiones ya elaboradas en agendas teológicas de reformas en la Iglesia. Los estándares contemporáneos de buena gobernanza que se demandan coinciden en buena medida con la necesidad del desarrollo de una sinodalidad estructural.

Palabras clave: clericalismo, sistema de gobernanza, accountability, sinodalidad, Royal Commission into Institutional Responses to Child Sexual Abuse.

Abstract: The issue of sexual abuse of minors constitutes one of the most significant crises of the Catholic Church in the modern era. In the first place, this article offers several arguments for the understanding of the subject from specialized North American texts. The second moment represents the core of the contribution: with the analysis of several reports of different nationalities, particularly Australian and German, the institutional aspect of the issue that occurred in the Catholic Church is highlighted, especially its systemic dysfunctions, which, as depicted with various arguments, converges with reflections already elaborated in theological agendas of reforms in the Church. The contemporary standards of good governance that are demanded coincide to a large extent with the need for the development of a structural synodality.

Keywords: clericalism, governance system, accountability, synodality, Royal Commission into Institutional Responses to Child Sexual Abuse. 


\section{Introducción $^{1}$}

No pocas personas consideran que el desafío que enfrenta la Iglesia a nivel internacional en relación con los abusos sexuales de menores constituye una de sus crisis más significativas en la era moderna ${ }^{2}$. No obstante, aunque justamente se pone especial atención en el comportamiento institucional de la Iglesia Católica, no es posible olvidar la dimensión social más general del fenómeno con cifras muy preocupantes; con un altísimo grado de impunidad, además. En el caso de Chile, por ejemplo, según cifras del Ministerio Público de 2016, se reciben unas 15.000 denuncias por delitos sexuales con menores al año. Las cifras chilenas de este tipo de abuso, presentadas por el Instituto Nacional de Derechos Humanos, están en línea con las que UNICEF individualiza a nivel mundial; si un $70 \%$ de niños/as sufren algún tipo de violencia, se estima que uno o una de cada diez sufre abuso sexual ${ }^{3}$. En cualquier caso, no hay dudas acerca del importante significado de lo sucedido para el reconocimiento social del problema: "la crisis de abuso sexual infantil en la Iglesia Católica, que surgió a raíz del debilitamiento de la autoridad tradicional, fue posiblemente el factor decisivo para fomentar la indignación dentro de la comunidad internacional y para incitar a los gobiernos a responder" ${ }^{\prime \prime}$.

El acento en el aspecto sistémico del problema, como se hace en esta contribución, no debe opacar una perspectiva más básica, de humanidad, o más precisamente de inhumanidad, que revelan los relatos de las víctimas: la falta de empatía, comprensión y acompañamiento por parte de los líderes eclesiales que se repite en los más diversos casos y regiones. La carencia de la sensibilidad por las víctimas es una ausencia llamativa. De manera análoga, no idéntica, a otras situaciones históricas es necesario

1 Este texto se enmarca en el proyecto de investigación Fondecyt No 1190556.

2 Cf. M. Faggioli, “The Catholic Church's Biggest Crisis Since the Reformation”, en https://www.foreignaffairs.com/articles/world/2018-10-11/catholic-churchs-biggest-crisis-reformation?cid $=$ soc-tw-rdr.

3 Cf. https://drive.google.com/file/d/1FPIewTCezEr4xK4B7Dn073oc_pNsjM5h/ view

4 K. Wright, "Remaking Collective Knowledge: An Analysis of the Complex and Multiple Effects of Inquiries into Historical Institutional Child Abuse", en Child Abuse \& Neglect 74 (2017) 10-22, 14. (Todas las traducciones de los diversos textos citados me pertenecen). 
preguntarse en el ámbito eclesial qué tipo de condicionamientos mentales y teológicos, qué formas culturales y prácticas organizacionales hicieron posible, facilitaron esta ceguera. Estos mecanismos deben ser desnudados para poder ser revisados.Por otro lado, no hay que minusvalorar las dificultades que presenta el desafío de poner el interés de las víctimas en el centro de la atención en las más diversas decisiones que deben proponerse y ejecutarse en la compleja realidad política civil y eclesial frente a los abusos. Si se revisan, por ejemplo, las varias normas de procedimiento previstas por la Conferencia episcopal australiana en su documento de 2010, Towards Healing, ( $\mathrm{n}^{\circ}$ 34-46), podrá advertirse inmediatamente la complejidad de factores y situaciones diversas a tener en cuenta ${ }^{5}$. En años recientes se han publicado múltiples textos de episcopados, de investigadores/as pertenecientes a distintas universidades, también de organismos estatales que, poco a poco, colaboran a la comprensión de un fenómeno muy complejo, ante todo, el del mismo trastorno psiquiátrico de la pederastia. Quien se aproxime a estos diversos informes podrá advertir que hay más preguntas que respuestas, que a menudo se acumulan variadas interpretaciones sin que sea posible arribar a un diagnóstico concluyente. No obstante, es posible advertir, también, que mucha información relevante está a disposición y que no pocos consensos iluminan el camino a recorrer. Sería de desear que esta información ya disponible tenga una mayor difusión. Es necesario elevar la calidad del diálogo público, también el que se realiza en los ambientes eclesiales ${ }^{6}$.

5 Australian Catholic Bishops Conference and Catholic Religious Australia, "Towards Healing. Principles and Procedures in Responding to Complaints of Abuse against Personnel of the Catholic Church in Australia", en https://www. catholic.org.au/professional-standards/towards-healing. Originalmente publicado en 1996, fue revisado en el año 2000 y nuevamente en 2010.

6 Las severas y detalladas críticas formuladas por Peter Steinfels, ex editor de Commonweal y profesor emérito de la Universidad de Fordham, al Grand Jury Report of Pennsylvania hecho público en agosto de 2018, con una enorme repercusión pública no solo en los Estados Unidos, invita a ser prudente y crítico en relación a todos los documentos que se publican, cualquiera sea su autor. Cf. "The PA Grand-Jury Report: Not What It Seems”, https://www.commonwealmagazine.org/pa-grand-juryreport-not-what-it-seems. Igualmente, las críticas observaciones, varias semejantes a las de P. Steinfels, de V. MilLer al informe australiano, que se cita más abajo, son también muy relevantes. Cf. "Speaking the Truth in Love (Eph. 4:15): An Analysis of the Findings of the Royal Commission into Institutional Responses to Child Sexual Abuse", en St Mark's Review 245 (2018) 23-49. 
Esta preocupación motiva, particularmente, el primer punto de esta contribución que se concreta, ante todo, mediante la revisión de unos textos norteamericanos acreditados ${ }^{7}$. Debido a los límites de extensión se ofrece aquí solo una indicación de un necesario camino a recorrer. El segundo paso de este artículo constituye el núcleo del aporte: a partir de varios informes de diferentes nacionalidades, sobre todo australiano y alemán, se pone de relieve el aspecto sistémico del asunto que, como se muestra, converge con aspectos ya elaborados en agendas teológicas de reformas en la Iglesia.

En el futuro investigadores/as, profesores/as, alumnos/as y, en general, distintos tipos de lectores revisarán nuestras revistas especializadas de teología, normalmente vinculadas a facultades o institutos de estudios teológicos, para verificar en qué medida, hasta qué punto y en qué forma esta generación enfrentó una crisis muy significativa de la Iglesia en la era moderna. No hay duda de que teólogos y teólogas tenemos aquí un asunto de responsabilidad. Sobre todo, porque en esta crisis se ha manifestado de modo convincente que los factores teológicos han sido -y continúan siendo- ingredientes constitutivos del problema y que una nueva visión eclesiológica implementada institucionalmente de manera coherente es parte insustituible de una solución progresiva.

\section{Una realidad compleja - Un informe norteamericano importante (2011)}

En junio de 2002, la Conferencia episcopal de los Estados Unidos en su reunión general en Dallas aprobó la "Carta para la Protección de Niños/as y Jóvenes" (Charter for the Protection of Children and Young People).

7 Además de los referidos en esta contribución, cf. en Holanda: The Commission of Inquiry, conocida como DEETMAN COMMISSION, concretó un estudio independiente sobre lo sucedido entre los años 1945 y 2010; lo publicó en diciembre de 2011; un resumen inglés: http://bishopaccountability.org/reports/2011_12_16_Deetman_ Seksueel_Misbruik/Deetman_Report_English_Summary.pdf. Como en el caso alemán, esta comisión fue formada por la misma Conferencia episcopal holandesa. Cf. también K. Demausure - B. Maisah, "L’abus sexuel des enfants: Péché ou pathologie? Une réflexion interdisciplinaire sur la question", en Studia Canonica 49 (2015) 139-160. 
Entre otras iniciativas, dicha Carta creó una Junta Nacional de Revisión (National Review Board) ${ }^{8}$, a la que le asignó la responsabilidad de supervisar la finalización del estudio de las causas y el contexto de la crisis que, en ese año, tuvo un momento muy peculiar debido a los recientes sucesos públicos de Boston. La Junta Nacional de Revisión contrató al John Jay College of Criminal Justice de la City University of New York para realizar investigaciones, analizar los datos recopilados y presentar un informe con los resultados a la Conferencia episcopal.

Dicho informe-titulado "The Causes and Context of Sexual Abuse of Minors by Catholic Priests in the United States, 1950-2010"- resume los resultados de un estudio empírico de las causas y el contexto del fenómeno del abuso sexual de menores por sacerdotes católicos en los Estados Unidos entre 1950 y $2010^{\circ}$. Es el segundo de dos estudios producidos por investigadores del John Jay College of Criminal Justice sobre los abusos sexuales cometidos por sacerdotes católicos. El primer estudio, publicado en febrero de 2004 -The Nature and Scope of Sexual Abuse of Minors by Catholic Priests and Deacons: 1950-2002-, se centró en la descripción y el alcance del problema desde 1950 hasta $2002^{10}$. Nature and Scope proporcionó información sobre lo que ocurrió, incluido el número de incidentes de abuso, la distribución geográfica y temporal de los delitos, las características de los sacerdotes contra los cuales se hicieron denuncias y los menores a los que abusaron, la respuesta de la Iglesia Católica a las acusaciones y también sobre el impacto financiero.

8 http://www.usccb.org/about/child-and-youth-protection/the-national-reviewboard.cfm

9 http://www.usccb.org/issues-and-action/child-and-youth-protection/upload/TheCauses-and-Context-of-Sexual-Abuse-of-Minors-by-Catholic-Priests-in-the-UnitedStates-1950-2010.pdf

10 http://www.usccb.org/issues-and-action/child-and-youth-protection/upload/TheNature-and-Scope-of-Sexual-Abuse-of-Minors-by-Catholic-Priests-and-Deaconsin-the-United-States-1950-2002.pdf 
El segundo estudio - Causes and Context- procuró comprender las causas del abuso sexual de menores integrando en la investigación perspectivas socioculturales, psicológicas, situacionales y organizacionales ${ }^{11}$.

Un factor que no es secundario, también destacado en los informes sobre Australia, si bien admite diversas explicaciones, muestra que una concentración de denuncias de abusos se verificó de modo creciente en los años 60', alcanzó su peak al final de la década de 1970, fue seguida de una sensible y rápida disminución de las denuncias a partir de mediados de los años $80^{\prime}$ y continúa en un número bajo hasta la actualidad. Esta disminución se verifica también en la sociedad en general, aunque más notablemente en la Iglesia Católica ${ }^{12}$. Los resultados del estudio Nature and Scope (2004) indicaron que el número total de sacerdotes con denuncias desde 1950 hasta el año 2002 fueron 4.392 de un total de 109.694 sacerdotes activos en el ministerio en algún momento durante ese período

11 El juicio emitido sobre estos dos informes por el interesante estudio de D. CAHILL y P. Wilkinson, Child Sexual Abuse in the Catholic Church: An Interpretive Review of the Literature and Public Inquiry Reports (RMIT University, Melbourne 2017) 76, sin desconocer sus limitaciones, es indicativo: "los dos informes de John Jay representan el estudio más exhaustivo, comprehensivo y empírico de todo un presbiterio nacional y sus abusadores sexuales de niños jamás realizado en los más de 2000 años de historia de la Iglesia con investigadores profesionales de ciencias sociales." Sus limitaciones las advierten, por ejemplo, en que los autores no apreciaron plenamente los factores culturales de la Iglesia; habrían descuidado igualmente los problemas teológicos y pastorales subyacentes, especialmente el rechazo de muchos obispos después de 1985 y hasta 2002, etc. "Su discusión sobre la oportunidad situacional fue muy sofisticada, basándose en sus antecedentes criminológicos, al igual que la sección de cómo los sacerdotes justificaron sus acciones abusivas y minimizaron el daño causado... Sin embargo, minimizaron seriamente el tema del secreto, los archivos secretos y la obediencia." El texto de Cahill y Wilkinson, de casi 400 páginas, ofrece un panorama actualizado de la documentación internacional disponible. "Como Polonia, España presenta un enigma..." (pág. 90); y sobre Italia: "Es imposible decir qué tan grave es el problema en Italia, porque no hay fuentes confiables” (pág. 92). El análisis de 16 informes pertenecientes a diversos países los conduce a una conclusión importante: "La respuesta episcopal católica en los distintos países del mundo ha sido notablemente uniforme" (pág. 96). Este informe, a diferencia de todos los otros citados en esta contribución, muestra la importancia de considerar un espacio de tiempo más amplio, no solo a partir de la década del 40' o 50'.

12 Cf. John Jay College, "Causes and Context", 2, 13. 
de tiempo; equivalente, por tanto, al 4 por ciento ${ }^{13}$. Los procesos, en líneas generales, son comunes a todas las regiones del país. En este marco deben entenderse las siguientes importantes constataciones que requieren ser apreciadas en su justa medida:

"El fenómeno del retraso en los informes, junto con la convergencia de incidentes en un período de tiempo particular, hace que la 'crisis' del abuso sexual sea un problema histórico. Esto no sugiere que los incidentes de abuso no hayan ocurrido recientemente y que no volverán a ocurrir en el futuro; sin embargo, la crisis, que involucró un alto número de incidentes de abuso sexual, que se elevaron en un momento determinado, ha pasado" ${ }^{14}$.

Otro aspecto para tener en cuenta y comprender el problema es descrito en estos términos:

"A pesar de los datos que indican que la incidencia de abusos aumentó de manera constante entre 1950 y 1980 y disminuyó considerablemente a mediados de la década de 1980, la mayoría de estos eventos eran desconocidos para las autoridades civiles o los líderes de la Iglesia Católica antes de 2002. Entre 1950 y 1985, el número total de incidentes de abuso sexual de niños que

13 Cf. John Jay College, "Causes and Context", 8, 3: "Menos del 5 por ciento de los sacerdotes con alegatos de abuso han exhibido comportamientos consistente con un diagnóstico de pedofilia (un trastorno psiquiátrico que se caracteriza por fantasías recurrentes, impulsos y conductas con niños prepubescentes). Por lo tanto, es inexacto referirse a los abusadores como 'sacerdotes pedófilos'." A partir del Diagnostic and Statistical Manual of Mental Disorders (DSM), en su cuarta edición, publicado por la AmERICAN PSYCHIATRIC AsSOClation, que contiene una clasificación y criterios para el diagnóstico de desórdenes mentales, el informe describe la pedofilia como "un trastorno psiquiátrico caracterizado por el interés en niños prepúberes. La versión actual del DSM describe los criterios de diagnóstico para este trastorno como una constelación de fantasías, impulsos o comportamientos relacionados con la actividad sexual con un niño pequeño (a menudo de trece años o menos). El individuo en cuestión debe sentirse principalmente atraído sexualmente por los niños prepúberes y debe experimentar estas fantasías, impulsos o conductas durante al menos seis meses consecutivos. Además, el individuo debe haber actuado sobre estas fantasías o impulsos con un niño, o las fantasías e impulsos ser excesivamente angustiantes hasta el punto en que la vida personal u ocupación del individuo se vea afectada negativamente." Cf. John Jay College, "Causes and Context", 124. Cf. E. Bridge - N. Duman, "Identifying Pedophilia", Life Skills Journal of Psychology 2 (2018) 215-222.

14 Cf. John Jay College, "Causes and Context”, 26.(cursiva mía) 
se reportaron a las diócesis católicas en los Estados Unidos fue de 810; el total reportado ahora de lo que ocurrió en ese período supera los $11.000 " 15$.

Estudios que emplean variadas metodologías estarían sugiriendo -"una conclusión provisional"- que, si un número de abuso adicionales todavía no conocidos y denunciados fueran reportados a las diócesis, los años de mayor incidencia, ya señalados, y la tasa de aumento o disminución no cambiarían ${ }^{16}$. A la luz de estos números y tendencias tan constantes y definidas, un argumento no secundario emerge repetidamente en el informe: los factores que se mantuvieron constantes durante este período de tiempo, como el celibato, "no explican la 'crisis' del abuso sexual. El celibato ha sido constante en la Iglesia Católica desde el siglo XI y no pudo explicar el aumento y la subsiguiente disminución de los casos de abuso por parte de la Iglesia Católica de los años 60 hasta mediados de los años $80 " 17$. Por otra parte, al considerar esas tendencias y los cambios experimentados en los planes de formación sacerdotal -asumiendo como pilar el factor humano, además del espiritual, pastoral e intelectual- en particular a partir de 1992 y muy especialmente en la primera década del nuevo milenio, otra reflexión parece adecuada: "La formación del seminario ha evolucionado considerablemente en los últimos veinticinco años, y esta evolución, probablemente (likely), tuvo un impacto en las tasas cambiantes de abuso sexual de menores" ${ }^{\prime 18}$.

15 Cf. John Jay College, "Causes and Context", 27.

16 Cf. John Jay College, "Causes and Context", 32.

17 Cf. John Jay College, "Causes and Context", 46.

18 Cf. John Jay College, "Causes and Context", 46. El estudio citado de D. Cahill y P. Wilkinson, Child Sexual Abuse in the Catholic Church, 186-187, individualiza diez razones para esta disminución, las que tienen que ver con una mayor visibilidad y vigilancia, mejores mecanismos de protección, incluso legislativos, menor cantidad de ministros activos, la fuerte reducción de los institutos implicados, el colapso del sistema de monaguillos al servicio del altar, la reducción de la participación en el sacramento de la reconciliación, la menor interacción entre sacerdotes y estudiantes católicos en las escuelas confiadas ahora en mayor medida a laicos/as, también el argumento destacado de la inclusión de la formación humana en los seminarios, etc. Análogamente se individualizan una serie de factores que explicarían los altos números de abusos en las décadas del 60' y 70': las turbulencias después del Vaticano II y el impacto de la llamada revolución sexual, junto a otros, son factores relevados, pero una focalización solo en ellos representaría una simplificación (págs. 192-193). 
De allí se desprende una perspectiva relativamente alentadora:

"En los últimos veinticinco años una notable intensificación de la formación humana y una comprensión más profunda de la importancia de su papel son evidentes en casi todos los seminarios. Durante el mismo período, el número total de acusaciones de abuso sexual de un menor por parte de un sacerdote católico se redujo de 975 durante el período de 1985 a 1989 a 253 durante el período de 1995 a 1999, y luego a 73 durante el período de 2004 hasta 2008. Una conciencia del problema del abuso sexual seguramente impactó en el desarrollo del currículo, pero los beneficios para los seminaristas pueden verse en los niveles muy bajos, continuos, de abuso sexual de menores" ${ }^{\prime 19}$.

En esta línea de argumentación se comprende, igualmente, la siguiente observación. Es crucial reconocer, también, que "el abuso se concentró

19 Cf. John Jay College, "Causes and Context", 47. En relación a los análisis psicológicos de los sacerdotes abusadores una conclusión puede sorprender: "La conclusión más significativa que se extrae de estos datos es que ninguna característica singular psicológica, de desarrollo o de comportamiento diferencia a los sacerdotes que abusaron de menores de los que no." Tomados en conjunto los datos de archivos clínicos, entrevistas y estudios psicológicos de varios informes "confirman acerca de los abusadores sacerdotes lo que se sabe sobre los abusadores no sacerdotes: no hay una sola 'causa' identificable del comportamiento de abuso sexual hacia los menores, y hay pocas características individuales que harían identificables a los abusadores con anterioridad a la comisión de sus actos abusivos. A pesar de que algunos factores de riesgo generales estuvieron presentes en los sacerdotes que abusaron de menores, este grupo no se distinguía de los sacerdotes que fueron tratados por otras razones. Esto es consistente con un meta-análisis reciente, que mostró que pocos factores de riesgo diferenciaron a hombres que abusaron sexualmente de niños de hombres que cometieron ofensas sexuales contra adultos". Cf. John Jay College, "Causes and Context", 74. Análogamente, se afirma: "La heterogeneidad de la población de sacerdotes abusadores presenta una agenda compleja para la prevención. No es posible identificar la mayoría de los posibles abusadores con las evaluaciones de psicología tradicional, porque muy pocos sacerdotes-abusadores fueron impulsados a cometer sus delitos por trastornos psicológicos diagnosticables", JOHN JAY College, "Causes and Context", 120. Por eso el texto afirma con mucho realismo: "Sabiendo que la mayoría de los abusadores potenciales no serán identificados antes de que ocurra el abuso, y sabiendo que muchos sacerdotes tienen vulnerabilidades que pueden llevar a cometer comportamientos desviados, es importante reducir las oportunidades para que ocurra el abuso.", John Jay College, "Causes and Context", 121. 
en las décadas de 1960 y 1970 y que esas generaciones de sacerdotes católicos eran vulnerables sin haber tenido una cuidadosa preparación para una vida célibe o la comprensión del daño del abuso sexual, comprensión que ahora es parte de la cultura general" ${ }^{20}$. La mayoría de los abusadores $(70 \%)$ fueron ordenados antes de la década de 1970, y más abusadores fueron educados en seminarios en las décadas de 1940 y 1950 que en cualquier otro período de tiempo ${ }^{21}$.

El informe reconoce los cambios introducidos a partir de 2002 en los Estados Unidos, pero advierte que estas transformaciones se hicieron por la presión exterior, proponiendo, además, una comparación poco elogiosa, esto es, la forma de operar de la organización policial:

“...como en la mayoría de las organizaciones, estos cambios se produjeron después de un caso de alto perfil de un abusador extremo (en este caso, J. Geoghan) que se publicó ampliamente en los medios de comunicación. Como tal, la percepción pública fue que el cambio llegó demasiado tarde y solo en respuesta a la publicidad negativa asociada con la crisis, en lugar de preocuparse por las víctimas. Este patrón de respuesta es similar a otras organizaciones, particularmente a la policía. La policía a menudo promulga nuevas políticas para supervisar la corrupción y la brutalidad después de la formación de Comisiones para evaluar los abusos de poder policial. Al igual que la policía, la Iglesia también se basó en gran medida en sus mecanismos internos de revisión del comportamiento. La falta de transparencia externa, junto con la falta de rendición de cuentas (accountability), además, generó la preocupación del público acerca de la respuesta de la Iglesia a este grave problema"22.

Otro factor destacable para la comprensión del problema es la relativamente tardía emergencia de los estudios sobre la victimización y, en particular, la comprensión de la profundidad del daño ocasionado por el abuso infantil. "Los estudios sobre el daño y la prevalencia de la

\footnotetext{
20 John Jay College, "Causes and Context", 74.

21 Cf. John Jay College, "Causes and Context", 118.

22 John Jay College, "Causes and Context", 93.
} 
victimización comenzaron a surgir en la década de 1970, pero no recibió una amplia atención de los medios hasta la década de 1980.” En ese contexto debe ubicarse la siguiente constatación:

"Al igual que el público en general, los líderes de la Iglesia no reconocieron el alcance o el daño de la victimización. El enfoque de los obispos hasta ese momento estaba en el sacerdote-abusador. Este enfoque fue paralelo al de la investigación concurrente, que fue, principalmente, sobre los delincuentes sexuales y su tratamiento. Lamentablemente, esta falta de reconocimiento del daño a la víctima es un factor que probablemente condujo a la continua perpetración de delitos" ${ }^{13}$.

Un elemento colaboró a no profundizar en el daño producido: el informe norteamericano, Causes and Context, muestra que hay poca evidencia de que los líderes diocesanos se reunieran directamente con las víctimas antes de 2002. La respuesta se centró en los sacerdotes abusadores en lugar de hacerlo en las víctimas. En la mayoría de las diócesis se tomaron medidas para ayudar a "rehabilitarlos".

Dos factores deben ser puestos en conexión para iluminar otro aspecto del asunto. Por una parte, "la constancia de los datos indica que la oportunidad juega un papel importante en la elección de las víctimas". Por otra, se advierte que, durante el peak de los casos de abuso en la década de 1970 y principios de la década de 1980, "existían pocos 'guardianes capaces' que podrían haber evitado que ocurriera el abuso. La victimización se entendió poco, los signos de los abusos no se reconocieron fácilmente, los niños pasaron tiempo solos y sin supervisión con los sacerdotes, y el abuso generalmente no se informó hasta años después de que ocurrió" 24 . Las políticas de prevención, por lo tanto, "deben centrarse en tres factores: educación, modelos de prevención situacional, y supervisión y rendición de cuentas (accountability)" 25 .

Otra observación que a menudo aparece en los diversos informes

23 John Jay College, "Causes and Context", 98.

24 John Jay College, "Causes and Context", 102, 117 respectivamente. La primera constatación explica por qué una de las medidas más oportunas en políticas de prevención se orienta a dificultar las oportunidades para que el abuso tenga lugar.

25 John Jay College, "Causes and Context”, 120. 
reside en la novedad de los estudios a partir de sus distintos enfoques. Esto permite prever que recién estamos a los inicios de poseer una información de mayor calidad, mucho más diferenciada. Un ejemplo tomado de The Causes and Context en referencia directa a la Iglesia Católica: "Ninguna otra institución ha realizado un esfuerzo similar y, como tal, esta investigación y sus resultados son una oportunidad única para adquirir conocimiento sobre el abuso sexual de menores dentro de una institución y para comprender la respuesta de una organización a este problema"26.

\section{2. "Disfunciones sistémicas" en la Iglesia Católica}

En fecha más reciente se han publicado documentos importantes en Australia y Alemania. Son textos de naturaleza diversa desde distintos ángulos, sea por su autoría, por su extensión o, también, por sus objetivos. En las páginas siguientes procedo de esta manera: primero, presento brevemente los dos informes referidos (2.1.), en segundo lugar, destaco la importancia de realizar una recepción teológica de ellos (2.2.), tercero, combino, sin tratarlos en puntos separados, argumentos extraídos de esas fuentes y reflexiones propiamente eclesiológicas (2.3. y 2.4.).

\subsection{El "Informe final" australiano (2017) y el "Estudio" alemán (2018)}

Entre los años 2012 y 2017 una "Comisión real" -Royal Commission into Institutional Responses to Child Sexual Abuse- creada por las instancias gubernamentales de Australia se dedicó al análisis y a la formulación de propuestas referidas al abuso de menores entre los años 1950 y 2017 en las más variadas instituciones a nivel de todo el país. En el mes de diciembre de 2017 la comisión, conformada por personas de reconocido prestigio en el ámbito público australiano, presentó su informe -Final Report- en 17 volúmenes; uno de ellos, el 16 sobre las instituciones religiosas está subdividido en tres libros. El volumen 16: libro 2, de más de 900 páginas, está dedicado íntegramente a examinar a la Iglesia Católica ${ }^{27}$. La comisión tuvo aproximadamente 7.000 sesiones privadas en orden a escuchar 6.875 víctimas, 57 sesiones públicas con diferentes instituciones

\footnotetext{
26 Cf. John Jay College, "Causes and Context", 25.

27 Cf. Final Report. Volume 16. Religious Institutions. Book. 2, Commonwealth of Australia 2017. https://www.childabuseroyalcommission.gov.au/final-report
} 
(iglesias, escuelas, clubes de deportes, etc.) y una larga serie de diálogos con expertos pertenecientes a distintos ámbitos, entre ellos, también, con miembros de las iglesias, incluidas sus autoridades y teólogos/as.

El estudio alemán -"Abuso sexual de menores por parte de sacerdotes, diáconos y religiosos varones católicos en el área de la Conferencia episcopal alemana"-, por su parte, fue llevado adelante por investigadores/ as y profesionales pertenecientes a universidades y centros de salud por encargo de la misma Conferencia episcopal. Los objetivos del proyecto de investigación publicado en setiembre de 2018, que analizó el período entre 1946 y 2014, fueron: (1) determinar la estimación numérica de la frecuencia del abuso sexual de menores por parte de sacerdotes católicos, diáconos y religiosos varones en el área de la Conferencia episcopal alemana, (2) la descripción y análisis de las características de los actos de abuso, así como de los grupos acusados y afectados, (3) la identificación y análisis de las estructuras dentro de la Iglesia Católica que pueden facilitar la ocurrencia de estos $\operatorname{casos}^{28}$. El proyecto de investigación incluyó siete sub-proyectos (SP1 a SP7), cada uno de los cuales exploró diversas preguntas, escogió diferentes enfoques metodológicos y examinó diferentes muestras. Los resultados de los sub-proyectos en su conjunto, piensan los autores, "proporcionan una visión integral, diferenciada e integrada del abuso"29. Ellos son conscientes de los múltiples límites que tiene el trabajo, ante todo, la gran cantidad de información a la que, por diversos motivos, no tuvieron acceso. De allí que afirmen con cautela que, incluso por las metodologías utilizadas, "en el mejor de los casos, se pueden generar hipótesis sobre la base de los hallazgos existentes" ${ }^{\prime 30}$. Al mismo tiempo, advierten con claridad el aporte específico del trabajo realizado: el método de investigación elegido, esto es, utilizar fuentes de información que existían independientemente entre sí, combinar métodos de investigación cualitativos y cuantitativos e incluir competencias criminológicas, psicológicas, sociológicas y forense-psiquiátricas no había sido utilizado, en esta medida, en ninguno de los estudios nacionales e

28 Cf. "Sexueller Missbrauch an Minderjährigen durch katholische Priester, Diakone und männliche Ordensangehörige im Bereich der Deutschen Bischofskonferenz", Mannheim, Heidelberg, Gießen, 24. September 2018, 21. Cf. https://dbk.de/themen/sexueller-missbrauch/

29 "Sexueller Missbrauch", 3.

30 "Sexueller Missbrauch", 4. 
internacionales que se han publicado sobre este tema hasta la fecha. Ahora bien, más allá de la opinión de sus autores, el informe tiene una debilidad importante: no se trata, estrictamente, de un trabajo independiente de la iglesia alemana, ya que, precisamente, es el fruto de un encargo hecho por ella misma a personas pertenecientes a varias instituciones del país. El informe destaca, sin esconderlo, que la colaboración de las diócesis se ha concretado de manera desigual. Al final de su reunión anual, en setiembre de 2018, en la que hicieron público el informe, los obispos alemanes han formulado claramente el asunto: "Sin un examen o estudio independiente no puede haber cambio efectivo y justicia" 31 . El llamado "plan de siete puntos" allí formulado por los obispos parece tener una preocupación transversal, además de la prioridad de la perspectiva de las víctimas: instancias externas, independientes, expertas, en algunos casos, vinculantes. No obstante, también desde esta perspectiva el informe australiano tiene mayor valor.

\subsection{Una lectura teológica}

Naturalmente que un trabajo de esta naturaleza, me refiero ahora específicamente al informe australiano, contiene una serie de argumentos muy variados dirigidos a narrar lo sucedido, desentrañar causas que han posibilitado estas tragedias y sugerir recomendaciones directamente vinculadas a una política anti-abusos por parte de las más diversas instituciones y del mismo estado australiano. Pero una perspectiva me parece central -es el pretendido aporte específico de esta contribuciónesto es, una lectura desde una mirada teológica a un texto escrito bajo la responsabilidad de la comisión formada por dos jueces (varón y mujer), un fiscal con larga experiencia en la tarea policial, un abogado comercial con experiencia en distintas comisiones y departamentos públicos, una médica psiquiatra con particular dedicación a niños/as y adolescentes y un empresario, con experiencia docente y también política (senador por

31 "Erklärung der deutschen Bischöfe zu den Ergebnissen der Studie 'Sexueller Missbrauch an Minderjährigen durch katholische Priester, Diakone und männliche Ordensangehörige im Bereich der Deutschen Bischofskonferenz' anlässlich der Herbst-Vollversammlung der Deutschen Bischofskonferenz am 27. September 2018 in Fulda", https://www.dbk.de/fileadmin/redaktion/diverse_downloads/ presse_2018/2018-154a-Anlage1-Erklaerung-der-Deutschen-Bischofskonferenzzu-den-Ergebnissen-der-MHG-Studie.pdf 
Australia occidental). Es posible advertir en el texto citado una crítica que fundamenta, desde otra mirada, la agenda de reformas en la Iglesia, en buena medida ya estudiada y propuesta en los ámbitos teológicos, aunque nunca concretada en sus trazos esenciales ${ }^{32}$. En mi opinión, una conclusión emerge en la lectura: lo que ya sabíamos que era incorrecto desde el punto de vista teológico, ahora se comprueba que es, además, "un modelo no saludable" 33 como cultura humana e institucional y que esas insuficiencias -"disfunciones sistémicas" ${ }^{34}$ son factores que han contribuido y contribuyen todavía hoy a la inseguridad de las personas, especialmente la salud de los menores. Lo que se muestra mediante diversos argumentos es que hay una vinculación muy estrecha entre las insuficiencias institucionales con los problemas teológicos; una teología al uso que fundamenta, hace plausible, una forma de organización social "no saludable", es decir, que crea condiciones que facilitan el abuso y su perpetuación, su posterior encubrimiento. ¡La reforma de la Iglesia y las reformas en la Iglesia aparecen, por primera vez, como una imprescindible e impostergable política de salud pública!

El tipo de análisis, con sus diversos argumentos, que se ofrecen en estos informes y que se destacan en esta contribución, podrían ayudar, también, a hacer frente a una de las dificultades actuales, esto es, la diversidad de interpretaciones, que incluso en la misma Iglesia es posible detectar, acerca de las causas y de los posibles remedios de los abusos perpetrados. Se trata de un aspecto importante: sin un diagnóstico más o menos claro, fundado y compartido no es fácil imaginar una terapia adecuada. Pero, como se advierte en el debate internacional, la tarea no es sencilla puesto que los diferentes diagnósticos reflejan a menudo diferencias teológicas más o menos profundas que conviene advertir.

Dos aspectos quiero subrayar particularmente: la dimensión teológica

32 Entre la mucha bibliografía existente, cf. A. SpadAro - C. M. Galli (eds.), La reforma y las reformas en la Iglesia, (Sal Terrae, Maliaño, Cantabria, 2016); M. WIRz (ed.), Riformare insieme la Chiesa (Edizioni Qiqajon, Magnano 2016); C. SCHiCKENDANTZ, "La reforma de la Iglesia en clave sinodal. Una agenda compleja y articulada", Teología y Vida 58 (2017) 35-60.

33 Cf. Final Report. Volume 16. Book 2, 657.

34 J. O’Malley, “The Scandal: A Historian's Perspective”, en America (May 27, 2002), https://www.americamagazine.org/issue/374/article/scandal-historians-perspective 
del asunto, por una parte, y la dimensión sistémica del problema, no meramente individual, por otra.

En primer lugar, la dimensión teológica está explícitamente destacada en el informe australiano: "A lo largo de la Sección 13.11 consideramos cómo la teología se ha cruzado con factores que han contribuido a la ocurrencia del abuso sexual infantil en instituciones de la Iglesia Católica y sus respuestas institucionales inadecuadas a este abuso". Entre los factores teológicos causales se enumeran: la eclesiología, es decir, enseñanzas sobre la naturaleza de la Iglesia y su misión, incluidos los roles de liderazgo y ministerios; la teología del sacerdocio: incluidas las ideas del sacerdote como alter Christus, de "cambio ontológico", el carácter indeleble del sacerdocio, y el hecho de estar abierta esta posibilidad solo a varones; la teología de la sexualidad: ideas sobre el género, el cuerpo y la ética sexual; una teología del pecado y el perdón: ideas sobre la pecaminosidad y la redención humanas; pecados mortales (mayores) y veniales (menores), incluida la opinión de que todos los pecados sexuales son pecados mortales; la teología sacramental, incluida la importancia y el funcionamiento de los sacramentos del bautismo, las órdenes sagradas y la confesión o reconciliación ${ }^{35}$. El mero listado de las cuestiones teológicas implicadas, según la comisión australiana, da una idea de la complejidad del problema y de la importancia neurálgica del análisis que se propone. Naturalmente que un discernimiento teológico muy preciso y detallado es necesario para comprender cada uno de esos asuntos y, en particular, su posible implicación en los abusos ocurridos.

En segundo lugar, la dimensión sistémica, el informe destaca que sus propias investigaciones, la revisión de la literatura y de investigaciones previas "sugieren que una combinación de factores teológicos, históricos, culturales y estructurales u organizativos en la Iglesia Católica permitió que el abuso sexual infantil se produjera en las instituciones de la Iglesia Católica en Australia y contribuyó a respuestas institucionales inadecuadas" ${ }^{36}$. Entre esos factores relevantes, que "conforman un conjunto estrechamente interconectado de factores estructurales y culturales sistémicos", se incluyen: factores teológicos, incluida una imaginería patriarcal de Dios, la teología de la Iglesia y del sacerdocio; la

35 Cf. Final Report. Volume 16. Book. 2, 587-588.

36 Final Report. Volume 16. Book. 2, 616. 
cultura del clericalismo en la Iglesia Católica; la estructura organizacional y el gobierno de la Iglesia Católica; las limitaciones del derecho canónico; el celibato; la selección y formación inicial de clérigos y religiosos para el ministerio; la supervisión, apoyo y formación continua de personas en el ministerio pastoral; en general, una cultura de secreto en la Iglesia Católica ${ }^{37}$.

En este sentido, el informe australiano acentúa la perspectiva de que estamos frente a un asunto sistémico, organizacional. Expresamente advierte que la responsabilidad de la crisis de abuso sexual infantil "es generalmente considerada por los líderes de la Iglesia", por el contrario, como una realidad vinculada a "un pequeño número de sacerdotes individuales cuyos crímenes son el resultado del fracaso personal y de la pecaminosidad." Análogamente, se constata que "el liderazgo de la Iglesia tiende a responsabilizar a los obispos individuales por el hecho de que los casos de abuso no fueron tratados adecuadamente, en lugar de considerar un posible fracaso institucional" ${ }^{38}$. Observaciones semejantes es posible encontrar en otros informes internacionales ${ }^{39}$. El estudio alemán, por ejemplo, lo expresa con claridad: "El abuso sexual constituye siempre, también, un abuso de poder, y esto puede ser facilitado por las estructuras autoritarias y clericales de la Iglesia Católica" $"$. Por eso reclama un "cambio en las estructuras de poder clerical", es decir, "un examen fundamental

37 Cf. Final Report. Volume 16. Book 2, 616.

38 Final Report. Volume 16. Book 2, 585.

39 Cf. John Jay College, "Causes and Context", 92. Allí se enumeran los siguientes factores: "La estructura de oportunidades para el comportamiento abusivo se enfoca en cuatro factores: la autoridad de los sacerdotes, la percepción pública de ellos, el aislamiento de sus posiciones y el alto nivel de discreción y falta de supervisión en sus posiciones." El trabajo de la comisión irlandesa afirma: “cada caso de abuso sexual fue tratado de manera aislada y en secreto por las autoridades y no hubo ningún intento de abordar la naturaleza sistémica subyacente del problema", The Commission to Inquire into Child Abuse. Cf. el Executive Summary, del llamado Ryan Report, http:/ / www.childabusecommission.ie/rpt/ExecSummary.php. Creada por el gobierno, publicó un informe final en 5 volúmenes en marzo de 2009.

40 "Sexueller Missbrauch", 17. Cf. "Sexueller Missbrauch", 15: "Los resultados de la investigación muestran que el abuso de menores por parte del clero de la Iglesia Católica no es solo una mala conducta de los individuos, sino que se debe prestar atención al riesgo específico de la Iglesia Católica y las características estructurales que favorecen el abuso sexual de menores o dificultan su prevención”. 
del ministerio ordenado del sacerdote y de la comprensión de su papel con respecto a las personas no ordenadas." Y advierte con claridad: los reconocimientos verbales, la sanción de las personas individuales acusadas, el remordimiento público, el pago de las compensaciones financieras a las personas afectadas y el establecimiento de conceptos de prevención, etc., son necesarios, "pero de ninguna manera son medidas adecuadas." Si las respuestas de la Iglesia se limitan a tales medidas, esas disposiciones, positivas en sí mismas, podrían resultar incluso propicias "para preservar las estructuras de poder clerical, ya que solo apuntan a los sintomas de un desarrollo indeseable y, por lo tanto, impiden un debate sobre el problema fundamental planteado por el poder clerical"41.

\subsection{El clericalismo como el factor singular más relevante}

Si bien el informe australiano destaca como perspectiva global la "combinación de factores teológicos, históricos, culturales y estructurales u organizativos", individua al clericalismo como el factor singular más relevante: "Si uno tuviera que aislar un solo factor que ha contribuido a la respuesta tóxica de los líderes de la Iglesia Católica a las víctimas de abuso sexual, sería el clericalismo" ${ }^{2}$. Y, de manera análoga, poco más adelante: "nos parece que el clericalismo se encuentra en el centro, está interconectado con los otros factores y, en algunos casos, es la raíz o el fundamento de los otros factores que contribuyen"43. Es claro que el concepto de clericalismo a lo largo de la historia posee diversos significados, por ejemplo, en el marco de la relación iglesia-estado, la ya antigua pretensión acerca de un influjo excesivo e inadecuado de una

41 "Sexueller Missbrauch", 18

42 Final Report. Volume 16. Book 2, 613.

43 Final Report. Volume 16. Book 2, 616. En el documento alemán de setiembre de 2018, "Sexueller Missbrauch", 13, puede advertirse un matiz, el clericalismo aparece como "una causa importante": "El abuso sexual es, sobre todo, también un abuso de poder. El concepto de clericalismo se cita como una causa importante en este contexto y como una característica estructural específica del abuso sexual dentro de la Iglesia Católica (Doyle 2003). El clericalismo denota un sistema jerárquico-autoritario que puede llevar al sacerdote a adoptar una actitud de dominio sobre los individuos no ordenados en las interacciones, porque él ocupa una posición superior en virtud de su ministerio y ordenación. El abuso sexual es una manifestación extrema de tal dominio." Cf. https://dbk.de/themen/sexueller-missbrauch/ 
religión sobre la esfera política ${ }^{44}$. De allí que tenga sentido, en este contexto, ensayar siquiera una breve descripción. En este caso el informe refiere a la situación y organización intra-eclesial. Caracteriza al clericalismo como "la idealización del sacerdocio católico y, por extensión, la idealización de la Iglesia Católica institucional”"45.

"Surge de las dinámicas personales y sociales, se expresa en diversas formas culturales y, a menudo, se ve reforzado por las estructuras institucionales. Entre sus principales manifestaciones se encuentran un estilo autoritario de liderazgo ministerial, una cosmovisión rígidamente jerárquica y una identificación virtual de la santidad y la gracia de la iglesia con el estado clerical y, por lo tanto, con el clérigo mismo" ${ }^{46}$.

Representa un concepto equivocado de autoridad, de ejercicio del poder y del carácter especial de la persona ordenada al sacerdocio ministerial. De allí otra clara constatación del informe: “El 'escándalo' del fenómeno del abuso sexual en la Iglesia Católica es ante todo un problema del abuso profundo del poder eclesiástico" ${ }^{47}$. Estas observaciones sobre el poder, en el caso del documento alemán, también se individualizan cuando se constatan las dificultades para que el clero aprenda -se deje instruir- medidas de prevención; conforman una red clerical de difícil acceso que, incluso, no aprecia suficientemente el aporte especializado de laicos y laicas, constatan responsables de los programas ${ }^{48}$.

Puede advertirse aquí que la repetida idea formulada por el Papa

44 Cf. E. Garhammer, "Klerikalismus", en Lexikon für Theologie und Kirche. Bd. 6 (Herder, Freiburg i.Br. 1997) 130-131; R. Bucher, Priester des Volkes Gottes. Gefäbrdungen, Grundlagen, Perspecktiven (Echter Verlag, Würzburg 2010) 23-51.

45 Final Report. Volume 16. Book. 2, 613.

46 Final Report. Volume 16. Book, 2, 614 (cursivas mías).

47 Final Report. Volume 16. Book 2, 613.

48 Cf. "Sexueller Missbrauch", 199-200. Cf. 235: "En los estudios sobre abuso sexual en instituciones no católicas, la dimensión del poder también se cita como un factor clave que favorece el abuso". Al hablar de los lugares donde se abusa, se destaca el "máximo de autoridad" y el "mínimo de controles", p. 265. "La asimetría de poder al afectado es máxima”, p. 283 
Francisco acerca del clericalismo como principal factor responsable del abuso de conciencia, de poder y sexual encuentra en este informe un apoyo importante ${ }^{49}$. Una pregunta distinta es si, a nivel vaticano, se está percibiendo el problema prevalente o unilateralmente desde una perspectiva moral, individual (sea de la autoridad que falla o del victimario que delinque), es decir, si no está opacado o subvalorado el carácter estructural del asunto y si, por consiguiente, las acciones emprendidas por la Iglesia, a todos los niveles, están afrontando de modo apropiado la causa individuada del clericalismo: como un asunto de abuso de poder sistémico. La figura de una Iglesia sinodal utilizando la imagen de la "pirámide invertida" con la que se re-sitúa el ministerio ordenado al interior y al servicio del pueblo de Dios, en el que es quizás uno de los textos eclesiológicos más importantes en el pontificado de Francisco, indica una conciencia estructural, no solo de moralidad individual requerida a los pastores ${ }^{50}$. Pero es verdad que, incluso una vez asumido el carácter sistémico del asunto, queda abierta la pregunta acerca de su más exacta naturaleza.

49 La pregunta acerca de la vinculación entre la homosexualidad de los ministros ordenados y los fenómenos de abuso es un factor relevante en el debate actual. Sectores norteamericanos conservadores, particularmente, consideran a la homosexualidad como la causa principal del problema, descartando la centralidad del argumento del clericalismo. Los informes australiano y alemán son concordantes en este asunto. "La investigación sugiere que el abuso sexual infantil no está relacionado con la orientación sexual: Los perpetradores pueden ser heterosexuales, homosexuales, lesbianas o bisexuales. Las investigaciones han indicado que los hombres que se identifican como heterosexuales son tan probables como los hombres que se identifican como homosexuales para cometer un abuso sexual infantil", Final Report. Volume 16. Book 2, 612. Vincular ambas realidades - homosexualidad y pedofilia- es una "información errónea" que "no tiene base en investigaciones empíricas o respetables, conocimiento científico...", Final Report. Volume 16. Book 2, 603. Análogamente se expresa el estudio alemán, cf. "Sexueller Missbrauch", 17. La conclusión formulada en el estudio citado de D. CAhILl y P. Wilkinson quizás sintetiza bien los rasgos comunes de los estudios referidos: "La orientación homosexual no está directamente relacionada con el abuso sexual de niños, pero es un factor de riesgo significativo en aquellos sacerdotes y hermanos que no han resuelto satisfactoriamente su identidad sexual de una manera madura y adulta." Cf. Child Sexual Abuse in the Catholic Church, 251.

50 Cf. http://w2.vatican.va/content/francesco/es/speeches/2015/october/documents/papa-francesco_20151017_50-anniversario-sinodo.html 


\subsection{Un sistema de gobernanza inadecuado}

Las observaciones sobre la estructura jerárquica de la Iglesia y su sistema de gobernanza ocupan también un rol central en el texto australiano y sus argumentos, análogamente a los consignados más arriba, también han sido propuestos en reflexiones teológicas acerca de reformas necesarias en la Iglesia. En este punto se puede detectar, una vez más, la armonía o convergencia entre las críticas propiamente teológicas y las que provienen de expertos en otras ciencias, como las que refleja el informe australiano. Un ejemplo es muy elocuente:

"Los poderes de gobierno que individualmente tienen obispos diocesanos y provinciales no están sujetos a controles y equilibrios adecuados. No hay separación de poderes, y los aspectos ejecutivo, legislativo y judicial del gobierno se combinan en la persona del Papa y los obispos diocesanos. Los obispos diocesanos no han sido suficientemente responsables ante ningún otro órgano por su toma de decisiones en el manejo de denuncias de abuso sexual infantil o supuestos perpetradores. No ha habido ningún requisito para que sus decisiones sean transparentes o estén sujetas al debido proceso. Las consecuencias trágicas de esta falta de rendición de cuentas (accountability) se han visto en las fallas de quienes tienen autoridad en la Iglesia Católica para responder adecuadamente a las acusaciones y los sucesos de abuso sexual infantil" ${ }^{\prime 2}$.

Advertir que la administración de justicia es ilusoria si no existen tribunales independientes de las autoridades responsables de los gobiernos constituye una reconocida adquisición humanista de nuestra cultura. ¿Cómo debería posicionarse la Iglesia de cara a esta perspectiva en armonía con su propia constitución teológica, conforme al Evangelio, a la tradición y a la enseñanza magisterial, particularmente de los últimos concilios vaticanos? La evolución moderna de la eclesiología de controversia, como expuse en un ensayo de diagnóstico ofrecido en un texto publicado en $2015^{52}$, ha

51 Final Report. Volume 16. Book 2, 681 (cursivas mías).

52 Cf. C. Schickendantz, "Sinodalidad en todos los niveles. Teología, diagnóstico y propuestas para una reforma institucional", en V. AzCuY - C. CAAmaño - C. M. GALLI (eds.), La Eclesiología del Concilio Vaticano II. Memoria, reforma y profecía (Ágape libros, Buenos Aires 2015) 513-534, 527-528. 
custodiado sobre todo la "libertad" de la autoridad concretada en un dato preciso perseguido con perseverancia: su carencia de vinculación jurídica a otros sujetos en la Iglesia. Es sencillo verificar esta unilateralidad en muchos ejemplos en el derecho canónico vigente ${ }^{53}$.

Nadie puede asegurar que si estas consideraciones ya hubieran tenido un impacto relevante en la organización eclesial se podrían haber evitado abusos y sufrimientos injustos, pero es claro que la maduración políticocultural que se condensa en estas ideas y que caracteriza las instituciones actuales se orientó, precisamente, a prevenir abusos de poder, violatorios de los derechos humanos. Es un principio humanista de nuestra época que reclama un discernimiento: hay que sustituir la monarquización excesiva de la autoridad eclesial por una diversidad de poderes, la cual impida que, tanto en materia doctrinal como disciplinar, demasiadas cosas esenciales dependan de la voluntad de uno solo ${ }^{54}$.

Un ejemplo, entre otros posibles, que muestra una debilidad sistémica importante se advierte, en mi opinión, en un aspecto común a múltiples propuestas de conferencias episcopales, diócesis y congregaciones religiosas. La Charter for the Protection of Children and Young People de los obispos norteamericanos, revisada en 2011, no obstante sus muchos aspectos positivos, adolece de una laguna importante. Si bien prevé la creación de "una Junta de revisión que funcionará como un órgano consultivo confidencial para el obispo o eparca en el desempeño de sus responsabilidades" (Norms art. 4), deja sin precisar la necesidad ineludible de una consulta obligatoria a dicha Junta cuando una persona sola, el obispo o el eparca, decide si existe una "creencia razonable" o una "evidencia suficiente" de que ha ocurrido un abuso en orden a proseguir la investigación, incluyendo el envío a la Santa Sede si corresponde ${ }^{55}$. Una pregunta clave de un sistema gobernanza: ¿quién decide y cómo, mediante cuáles procedimientos la existencia de una "evidencia suficiente"?

53 Cf. S. Dianich, Riforma della Chiesa e ordinamento canonico (EDB, Bologna 2018) 69-78.

54 Con alguna modificación es la expresión de P. VALADIER, "Quelle démocratie dans l'Église?”, en Études 3882 (1998) 219-229, 228.

55 Cf. National Conference of Catholic Bishops, "Statements of the National Conference of Catholic Bishops and the United States Catholic Conference on the Subject of the Sexual Abuse of Children by Priests 1988-1992," (unpublished report, 1992) 10-11. 
Una persona individual -obispo, eparca, superior religioso/a, etc.- no debería poder tomar esa determinación sin que, de manera jurídicamente vinculante, se garantice un proceso de consulta que haga más probable una decisión acertada.

La carencia de esta vinculación jurídica a un comité externo y profesional es una señal de baja calidad institucional. Pareciera que no se aprende de los propios errores, de uno de los más comunes y repetidos incluso: obispos y superiores religiosos en los más diversos países, erróneamente, amparados en el derecho canónico que no se los exigía, no iniciaron o detuvieron investigaciones sin procedimientos de asesoramiento institucionalmente asegurados, sin tener que dar cuenta de su decisión a ninguna instancia personal o institucional ${ }^{56}$. La Charter norteamericana, explicablemente, no es una excepción en este punto: si se revisan los documentos episcopales irlandés, canadiense, australiano, chileno, mexicano, argentino, etc. se advierte la misma forma de proceder.

Ni el derecho canónico (cn. 1717 \& 1) ni la Carta circular de la Congregación de la Fe de 2011, "Subsidio para las Conferencias Episcopales en la preparación de Líneas Guía para tratar los casos de abuso sexual de menores por parte del clero", demandan otra $\operatorname{cosa}^{57}$.

En mi opinión, este es el panorama que puede observarse hoy: se crean juntas de revisión u organismos de asesoramiento en los episcopados,

56 Aquí hay otro punto evidente del derecho canónico necesitado de revisión: CIC cn. 1717 \1. "Siempre que el Ordinario tenga noticia, al menos verosímil, de un delito, debe investigar con cautela, personalmente o por medio de una persona idónea, sobre los hechos y sus circunstancias, así como sobre la imputabilidad, a no ser que esta investigación parezca del todo superflua.” ¿Cómo se decide que una investigación es "superflua" con una forma de proceder acorde a la calidad de gobernanza exigida en nuestro tiempo?

57 http://www.vatican.va/roman_curia/congregations/cfaith/documents/rc_con_ cfaith_doc_20110503_abuso-minori_sp.html. Tampoco el "modelo de líneas guía" de la Pontificia Comisión para la tutela de los menores de 2016 refleja conciencia del asunto (http://www.protectionofminors.va/content/tuteladeiminori/en.html). Igualmente, no parece que en la cumbre vaticana sobre abusos de febrero de 2019 se haya advertido el problema. La reflexión más próxima la ofrecen las presentaciones de Linda Ghisoni y Charles Scicluna; solo señalan los beneficios de estos "review boards or safeguarding commissions". Cf. las ponencias en http://www.vatican.va/ resources/index_it.htm 
diócesis y congregaciones religiosas, pero no se garantiza, incluso jurídicamente, su consulta ineludible. Se revela aquí una de las disfunciones sistémicas más comunes y, a la vez, más fundamentales en la Iglesia Católica en su modelo teológico-cultural actual: la discrecionalidad en el ejercicio de la autoridad. Creo que unas expresiones de Charles Scicluna en la cumbre vaticana de febrero de 2019 visibilizan bien el problema al que refiero: "En nuestro sistema, como se presenta actualmente, el papel de la víctima de abuso sexual en los procedimientos canónicos es limitado. La solicitud pastoral del Ordinario ayudará a compensar esta laguna"58. En otras palabras, por una parte, se reconoce que algunos derechos de las víctimas no están jurídicamente garantizados, por otra parte, el sistema legal de la Iglesia solo apela a la buena voluntad de las autoridades, a su "solicitud pastoral". El derecho no protege a la víctima, más bien salvaguarda la "libertad" o "autonomía" de la autoridad, es decir, no le exige de modo jurídicamente vinculante la conducta justa; en el caso aludido por Scicluna, transparencia y accountability, el deber de informar a las víctimas del progreso de los procedimientos judiciales. Quiero expresarlo con claridad a riesgo de equivocarme: no encuentro vestigios de un razonamiento tan elemental en ningún texto de la Santa Sede referido a estos asuntos.

La fundamentación teológica en la perspectiva de una Iglesia sinodal y, en particular, el principio de que el derecho puede establecer que "para realizar ciertos actos" un superior necesite del consentimiento o consejo de algún colegio o grupo de personas están ya formulados (CIC 127 S 1). Por tanto, no hay una objeción a esta posibilidad en línea de principio $\left(\right.$ CIC 127 \2) ${ }^{59}$. Además, esta vinculación ineludible puede concretarla cualquier tipo de autoridad de otra manera, sin necesidad de esperar una reforma en el derecho canónico: mediante una decisión voluntaria que, si bien el derecho no exige, tampoco prohíbe. La renuncia a determinadas

58 http://www.vatican.va/resources/resources_mons-scicluna-protezioneminori_20190221_en.html

59 Debe tenerse en cuenta que la distinción entre voto consultivo y voto deliberativo, aparentemente tan nítida, posee límites y no visibiliza inmediatamente los matices que se incluyen en ella; dichos conceptos, además, deben ser enriquecidos teológicamente, como muestra, por ejemplo, A. BorRAs, "Évolutions souhaitables en matière de synodalité sur le plan des 'instances intermeédiares", en L. BALDIsSERI (ed.), $A$ cinquant'anni dall'Apostolica sollicitudo. Il Sinodo del vescovi al servicio di una Chiesa sinodale (Libreria Editrice Vaticana, Città del Vaticano 2016) 263-296, 276-279. 
posiciones jurídicas obligándose a sí mismo voluntariamente es una posibilidad abierta a toda persona jurídica ${ }^{60}$. Por el contrario, estas perspectivas no parecen ni advertirse en estos textos oficiales; se trata de una "ingenuidad" en el ejercicio del poder que, a menudo, se la asegura con argumentos teológicos.

Creo, en particular, que, por una parte, las observaciones del informe australiano ya referidas y el ejemplo recién aludido confirman el "diagnóstico histórico-teológico" que ayuda a "comprender la situación en que nos encontramos" expuesto en el texto citado más arriba ${ }^{61}$. Por otra parte, queda claro que los desajustes estructurales que se observan en la Iglesia de hoy no pueden ser afrontados con meros llamados a la conversión individual o a la "solicitud pastoral". Este tipo de propuestas representan lo que Yves Congar caracterizaba como una "tendencia muy extendida entre los católicos"; se trata de la "tendencia a no ver más que el aspecto moral de los problemas", aquel aspecto moral "que depende de las intenciones y rectitudes de éstas." Es verdad que las actitudes puramente espirituales tienen su propia eficacia, causan impacto en las estructuras sociales, reconoce el autor. Pero, advierte, un enfoque moralespiritual es necesario, pero no suficiente. Existe una "densidad propia de las estructuras impersonales y colectivas" que debe tenerse en cuenta; "de lo contrario, las más generosas intenciones de reforma se agotarían en la tarea de recomenzar incesantemente un esfuerzo condenado siempre a una eficacia disminuida a causa de haber dejado intactas unas estructuras contrarias" ${ }^{\prime 2}$. Congar muestra ejemplos en la historia de la Iglesia, por una parte, de reformas espirituales ineficaces por haber prescindido de la renovación de las prácticas institucionales y, por otra, transformaciones altamente configuradoras de futuro -como la reforma gregoriana- por haber traducido en la organización, incluso jurídicamente, las ideas que las movilizaban. En la línea argumental de Congar, recientemente Serena Noceti ha recordado que estudios de sociología y ciencia política sobre las instituciones concuerdan en el hecho de que toda reforma se

${ }^{60}$ Existen ejemplos al respecto, cf. S. Demel, Zur Verantwortung berufen. Nagelproben des Laienapostolats (Herder, Freiburg i.Br. 2009) 81.

${ }^{61}$ Cf. C. Schickendantz, "Sinodalidad en todos los niveles", 518-525.

62 "Renovación del espíritu y reforma de la institución”, en Concilium 73 (1972) 326337, 329-330. Cf. W. Kasper, Katholische Kirche. Wesen - Wirklichkeit - Sendung (Herder, Freiburg i.Br. 2011) 61, 484. 
realiza interviniendo, al mismo tiempo, en tres niveles: en los contenidos de conciencia colectiva (visión), en la forma de las relaciones internas $\mathrm{y}$, finalmente, en las estructuras, los procedimientos, las actividades y funciones en los que se expresa y mantiene el cuerpo social. "Toda reforma que pretenda ser eficaz debe afrontar los tres niveles simultáneamente y de modo coherente"

La perspectiva del informe australiano converge con estos razonamientos, ilumina la verdad de estas palabras. Por el contrario, a partir de las acciones y declaraciones de los diversos actores pertenecientes a la curia romana y de otras instancias no parece que la dimensión sistémica comprendida en estos términos- sea asumida como ingrediente central del asunto. Esta última constatación pone en cuestión no solo la forma eficaz cómo se afronta este grave problema particular -el abuso de menores-, sino la concepción global y la eficacia permanente de los procesos de reforma en los que está empeñado el P apa Francisco.

El informe australiano incluye, también, otra advertencia acerca de la introducción de estructuras de gobernanza más inclusivas.

"La exclusión de los laicos y las mujeres de puestos de liderazgo en la Iglesia Católica puede haber contribuido a respuestas inadecuadas al abuso sexual infantil. De acuerdo con los estándares contemporáneos de buena gobernanza, alentamos a la Iglesia Católica en Australia a explorar y desarrollar formas en que sus estructuras y prácticas de gobernanza puedan hacerse más responsables (accountable), más transparentes, más significativamente consultivas y más participativas, incluso a nivel diocesano y nivel parroquial" ${ }^{64}$.

63 S. NoCeTI, "Estructuras para una Iglesia en reforma”, en Concilium 377 (2018) 84-99, 86-87.

64 Final Report. Volume 16. Book 2, 683 (cursiva mía). Otros argumentos referidos a "estándares contemporáneos de buena gobernanza", como por ejemplo la publicidad de los criterios de selección de obispos o una reforma a los procesos de nombramientos, como así también múltiples observaciones referidas al derecho canónico (tiempo y forma de las sentencias, publicación de las mismas, etc.) no son tratados aquí por razones de espacio. Sobre estos temas hay reflexiones, críticas y recomendaciones relevantes, particularmente en el informe australiano. 
De eso se trata, precisamente: estándares contemporáneos de buena gobernanza, no por una simple imitación acrítica de modelos políticos actuales, sino sobre todo por una convicción teológica que puede condensarse en la idea de una Iglesia sinodal, digna del Evangelio y de los justos requerimientos de nuestro tiempo (aggiornamento). Quizás la mayor dificultad teórica a la que nos enfrentamos es que amplios círculos eclesiales, guiados por una determinada formación o mentalidad, se oponen a algunas características esenciales de esos "estándares contemporáneos de buena gobernanza" con específicos argumentos teológicos, declarando a esos estándares como incompatibles con una eclesiología católica. De esta forma, invocando el nombre de Dios, se garantiza el statu quo. En buena medida, el liderazgo eclesial, a todos los niveles, guiado por esa mentalidad, no ha hecho suya una renovada visión eclesiológica. Por el contrario, dicho liderazgo continúa atrapado, mental y sistémicamente, en una cosmovisión "jerarcológica" que, como formulaba Y. Congar, privilegió "los derechos y el poder de sus autoridades" ${ }^{5}$. La impermeabilidad de este modelo y su probada resistencia a los cambios, en realidad, no debería sorprender: es un fruto, milenario al menos, bien consolidado $^{66}$.

Es verdad, también, que no se trata de trasponer a la Iglesia una concepción del estado, propia de la sociedad política. Precisamente la experiencia vivida con el modelo monárquico es aleccionadora. Hoy vemos mejor hasta qué punto la sumisión a un modelo político-cultural ajeno atenta contra una justa eclesiología. De allí que la estrategia no deber ser, de ninguna manera, el introducir la democracia en la Iglesia, una transposición acrítica, sino, en el marco de un diálogo y aprendizaje apropiado con las formas político-culturales de nuestro tiempo, la transformación a partir de las propias raíces, basada en una autocomprensión teológica de la Iglesia. Las razones teológicas para fundamentar "estándares de buena gobernanza" ya están contenidas en reconocidos conceptos con múltiples acentos y matices: la idea de Pueblo de Dios, de subjetividad bautismal, de carisma, de sinodalidad, de sensus fidei propio de todo el pueblo de Dios, etc. En cierto sentido, la Iglesia posee más argumentos que las

65 Citado en A. Dulles, Models of the Church (Image, New York $\left.{ }^{5} 2002\right) 27$.

66 Cf. G. LAFont, Imagining the Catholic Church. Structured Communion in the Spirit (Liturgical Press, Collegeville, MN 2000) 37-64; Y. Congar, Mon journal du Concile (Cerf, Paris 2002) I, 523. 
actuales democracias para concretar procesos de consultas y garantizar, incluso jurídicamente, espacios de discernimiento común y elaboración conjunta de decisiones: su convicción acerca de la presencia del Espíritu en cada persona al servicio del bien común ${ }^{67}$. Las reformas institucionales constituyen una cuestión pneumatológica.

Desgraciadamente la mayor incorporación de mujeres en distintos espacios eclesiales de discernimiento, liderazgo y gobierno, en particular, es todavía una tarea por realizar. Sorprende la falta de sensibilidad y de creatividad para llevar adelante un asunto tan significativo, cuya debilidad se advierte a todos los niveles de conducción en la Iglesia. Se repiten una y otra vez frases positivas en esta dirección en los más diversos documentos, pero ellos no encuentran ninguna traducción institucional significativa. El discurso sobre la sinodalidad de la Iglesia permanece, en buena medida, como una "imagen ideal" o una mera "retórica teológica" ${ }^{68}$. Es claro que, debido a una cultura institucional de varones muy arraigada, no se percibe la importancia cultural, epocal y la relevancia teológica de las justas exigencias puestas hoy por mujeres de todas las regiones de la tierra ${ }^{69}$. Debido a esta laguna, también, la Iglesia se priva a sí misma de estructuras más apropiadas para interpretar adecuadamente su tiempo a la luz del Evangelio. No se ponen los medios para ello.

\section{Reflexiones finales}

Tenemos una compleja tarea por realizar. Los pasos que se demandan requieren una aplicación de la metodología propuesta por el Concilio para los procesos de reforma y renovación tal como se formula, por ejemplo, en Perfectae caritatis 2: una doble fidelidad, simultánea (simul), al Evangelio y

${ }^{67}$ La importancia del consenso, por ejemplo, tiene profundas raíces históricas y teológicas. Cf. K. SCHATZ, "La sinodalità nella storia della Chiesa", en L. BALDisseri, A cinquant'anni dall'Apostolica sollicitudo, 31-47, 35, 44.

68 S. Demel, Zur Verantwortung berufen, 41, 57. Cf. también S. DiAnich, La chiesa cattolica verso la sua reforma (Queriniana, Brescia 2014) 107-121.

69 Cf. por ejemplo, M. ЕскноLт, Ohne die Frauen ist keine Kirche zu machen (Grünewald, Ostfildern 2012); M. A. HinsDale, "A Feminist Reflection on Postconciliar Catholic Ecclesiology”, en R. Gaillardetz - E. Hahnenberg (eds.), A Church with Open Doors. Catholic Ecclesiology for the Third Millenium (Liturgical Press, Collegeville, MN 2015) 112-137; V. AzcuY, "La situación tensionada de la Iglesia actual: cuatro retos fundamentales”, en Concilium 377 (2018) 46-58. 
a la rica y variada gran tradición de la Iglesia (ressourcement), por una parte, y a los justos requerimientos de nuestro tiempo (aggiornamento), por otra. Dicho discernimiento, por tanto, debe conceder relevancia particular a los estudios históricos. Con la conciencia, además, que "nuestra verdadera historia es la que nos puede salvar de la tiranía del presente" ${ }^{\text {". A }}$ A partir de perspectivas más amplias los líderes eclesiales deben atreverse a ir "más allá de las formas homologadas" actualmente. Como advertía Yves Congar en el texto más famoso del siglo XX sobre la forma prudente en que debe llevarse adelante una reforma eclesial:

"Si siempre se estuviese obligado a adoptar la forma de pensamiento teológico, de práctica religiosa o de organización actualmente en uso, no habría existido jamás en la Iglesia ni aggiornamento, ni reforma, ni progreso. (...) El problema de toda iniciativa profética es la de ir más allá no sólo de las formas actualmente en uso, de hecho, sino también más allá de las formas homologadas" $" 71$.

Y esta labor aparece como imprescindible al verificar el acierto, incluso gracias a estudios no generados desde la Iglesia y la teología, de un diagnóstico claro formulado por un autor que no despierta ninguna sospecha ideológica para sensibilidades más conservadoras, Avery Dulles: "Las actuales estructuras de la Iglesia, especialmente en el catolicismo romano, tienen una impronta muy fuerte de las pasadas estructuras sociales de la sociedad europea occidental" 72 . La peculiar concepción de la autoridad,

70 M. Colish, "Reclaiming our History. Belief and Practice in the Church", en F. OAKLey - B. Russet, Governance, Accountability and the Future of the Catholic Church (Continuum, New York 2004) 62-75, 75. Un ejemplo importante, cf. G. RugGIERI, "À propos des synodes: l'histoire nous interroge", en Recherches de Science Religieuse 106, 3 (2018) 363-382, 371, 373: en la situación actual, según la disciplina romana, un concilio constituye una reunión episcopal, pero esto "no tiene en cuenta la historia real de los concilios ecuménicos". El hecho de que el concilio en la historia hasta Trento haya sido pensado como repraesentatio ecclesiae, y no solo como modalidad solemne del ejercicio del poder supremo del colegio de obispos (CIC cn. 337.1), no es una diferencia menor. "En este desplazamiento se refleja el desplazamiento de la Iglesia, de la dimensión de pueblo de Dios y communio hacia el eje jerárquico y autoritario".

71 Cf. Y. Congar, Vera e falsa reforma nella Chiesa (Jaca Book, Milano ${ }^{21994)} 225 \mathrm{s.}$

72 A. Dulles, Models of Church, 191 
como se ha puesto de relieve en esta contribución, visibiliza particularmente ese modelo.

Para la tarea de aggiornamento el texto y el espíritu de Gaudium et spes 44, "La ayuda que la Iglesia recibe del mundo actual", ofrecen una orientación precisa. Se formula allí el principio acerca del aprendizaje que la Iglesia realiza gracias a "la ayuda" de quienes, "sean o no sean creyentes, conocen a fondo las diversas instituciones y disciplinas y comprenden con claridad la razón íntima de todas ellas" (GS 44, 2). Se afirma: la Iglesia por "disponer de una estructura social visible... puede enriquecerse, y de hecho se enriquece también, con la evolución de la vida social". Las razones y el objetivo son claros: "no porque le falte en la constitución que Cristo le dio elemento alguno, sino para conocer con mayor profundidad (profundius cognoscendam) esta misma constitución, para expresarla de forma más perfecta (melius exprimendam) y para adaptarla con mayor acierto (felicius accommodandam) a nuestros tiempos" (GS 44, 3). El contexto políticocultural concreto, esto es, "la evolución de la vida social humana", no es presentado aquí como destinatario o beneficiario de la acción eclesial. Por el contrario, los progresos sociales son percibidos como instancias o fuentes a partir de los cuales se produce un enriquecimiento en el conocimiento teológico, nada menos que una profundización en la "verdad revelada" (GS 44, 2). Antes del Concilio, la confrontación con la sociedad era cuestión, principalmente, de la doctrina social católica, caracterizada ésta por un enfoque metafísico-ontológico y por un procedimiento deductivo. Por el contrario, se advierte aquí una nueva manera de pensar que se hace cargo del carácter histórico y social del pensamiento mismo y que, de este modo, llega a dar una nueva definición de las relaciones entre Iglesia y sociedad. El sentido del número 44 es nítido: "la ayuda que la Iglesia recibe del mundo moderno". En este sentido, el institucional, sería un caso de lo que el mismo número 44 explicita como regla general: "a fin de que la Verdad revelada pueda ser siempre mejor percibida, mejor entendida y expresada en forma más adecuada" $(44,2)$. En el debate que afronta esta contribución se muestra que una visión sinodal de la Iglesia con sus ineludibles implicaciones en su "estructura social visible" no solo posee una fundamentación teológica apropiada, sino que responde más adecuadamente a las principales enseñanzas que se desprenden de "la evolución de la vida social humana" y que, en buena medida, hoy se materializan en los "estándares contemporáneos de buena gobernanza". 
En síntesis, el análisis ofrecido aquí y los varios ejemplos presentados muestran que varias de las postergadas reformas de la Iglesia y en la Iglesia constituyen un asunto capital, ya no solo para que ella sea en nuestro tiempo, de modo genérico, lo que ella está llamada a ser, como transparencia de Dios y de su Evangelio, "signo e instrumento" (LG 1), sino también para garantizar con mayores posibilidades de éxito la salud psíquica, espiritual y física de los niños y niñas de nuestras sociedades, los más vulnerables. La compleja política anti-abusos -que incluye los aspectos más diversos, como el poner en el centro a las víctimas, reglamentar de modo transparente los procesos de denuncia, garantizar la justicia con legislaciones adecuadas, ofrecer espacios de acompañamiento y de reparación con procedimientos apropiados a las diversas situaciones, implementar políticas de prevención en todas las instituciones, favorecer la formación de profesionales de diversas disciplinas, etc.-, constituye una tarea difícil no solo para la Iglesia, sino también para el Estado y las más diversas asociaciones. Pero, en el caso de la Iglesia Católica, esa agenda no es suficiente si no se afronta un "cambio en las estructuras de poder clerical"73. Pareciera que las perspectivas "estructurales", en la forma específica como están destacadas en esta contribución, no están siendo adecuadamente advertidas por muchas autoridades en la Iglesia. Hay que sacar enseñanzas apropiadas de lo que, a todas luces, se muestra como un "fracaso institucional" "74, sistémico y, por eso, como se ha verificado, global.

73 "Sexueller Missbrauch", 18.

74 Final Report. Volume 16. Book. 2, 585. La misma expresión usan los obispos alemanes al evaluar los "impactantes resultados" del estudio: "muestran un fracaso institucional". Cf. "Erklärung der deutschen Bischöfe". 


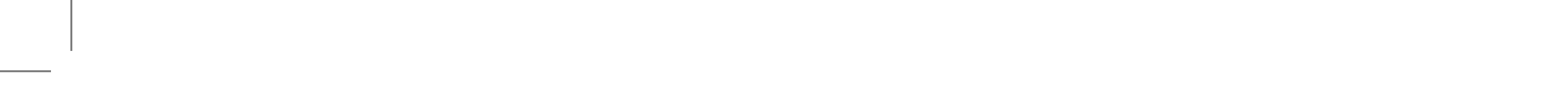

